\title{
Pathomorphology of Papilloma Tumor in Cattle Based on Macroscopic and Microscopic
}

\author{
Etriwati Etriwati ${ }^{1 *}$, Nazaruddin Nazaruddin ${ }^{1}$, Dwinna Aliza ${ }^{1}$, Denny Irmawati \\ Hasan $^{1}$, Rizki Akbar Siagian ${ }^{2}$ \\ ${ }^{1}$ Laboratory of Pathology, Faculty of Veterinary Medicine, Universitas Syiah Kuala, Banda Aceh, Indonesia \\ ${ }^{2}$ Study Program of Veterinary Medicine Professional Education, Faculty of Veterinary Medicine, Universitas Syiah \\ Kuala, Banda Aceh, Indonesia \\ *Corresponding author. Email: etriwati2102@unsyiah.ac.id
}

\begin{abstract}
Papilloma was a proliferative neoplasm which benign typically that affecting nearly all animal species. This study aimed to observed changes in the papilloma in cattle based on macroscopic and microscopic to determine the difference between the two samples. The sample used was papilloma which was suspected based on clinical symptoms in an Angus breed and Limousin cattle. The samples were processed in histopathological techniques and stained with hematoxylin-eosin. In clinically sign, neoplasms of various sizes were found and showed exophytic masses in several parts of the body. On the macroscopic examination on the Angus cattle were found sarcoid-shaped tumors on the neck and nodular forms such as cauliflower-like shaped on several parts of the body, black-gray in color and the rough surface on the tumor. Microscopically, hyperkeratosis, coliocytes, and acanthosis were found. On the macroscopic examination of the tumor in Limousin cattle, were found the tumors that in the nodular shape, yellowishwhite in color with a flat surface on the tumor. Microscopically, there was the proliferation of connective tissue in the dermis, hyperkeratosis, rete ridges, acanthosis and eosinophilic intranuclear inclusions. The conclusion of this study was found the differences by macroscopic and microscopic of the papilloma tumors in Angus and Limousin cattle.
\end{abstract}

Keywords: Anatomical pathology, cattle, histopathology, papilloma

\section{INTRODUCTION}

Papilloma tumors or warts are neoplasms that are found in almost all types of animals. In young cattle, warts are found around the neck. Papillomatosis is a benign type of neoplasm, for example, skin papilloma, fibro papilloma and also malignancy, for example, bladder cancer in cattle which causes considerable economic losses [1,2]. Bovine papillomatosis is a disease that attacks cattle with Papilloma (Warts) on the skin and mucosa caused by Bovine Papilloma Virus (BPV) subtypes 1, 2, 3, 4, 5, 6 which were isolated [3].

BPV is classified into 4 genera, namely: Xipapillomavirus, Deltapillomavirus, Epsilonpapillomavirus and Dyoxipapillomavirus. Genus Xipapillomavirus (BPV types 3, 4, 6 - previously in subgroups B - 9, 10, 11 and 12) infects the cause of papilloma epithelial keratinocytes while the genus Deltapapillomavirus (BPV types 1, 2 previously included in subgroups A and 13) causes fibropapilloma on the skin and urinary vesicles. BPV 5 causes fibropapilloma in the udder [4]. Papillomavirus not only causes papillomatosis in cattle but causes equine sarcoid in horses and canine oral papillomatosis in cats $[5,6]$.

Although BPV infection does not usually cause livestock death, it does cause slow growth, weight loss and decreased milk production [7]. Although the spread of disease is usually direct contact, many factors such as contaminated food and equipment, castration, injections, heredity, nutritional imbalances, hormonal imbalances, and decreased immune system may play a role in the spread of disease $[8,9]$.

Diagnosis of papillomatosis in cattle can be based on clinical symptoms, histopathological examination, using electron microscopy and immunohistochemical staining to detect papillomavirus in papilloma tissue [6, 10]. Histopathological view, varying degrees of hyperplasia of the epidermis with irregular papillary 
into the dermis, low to severe acanthosis in the epidermis, low to severe hyperkeratosis, hydropic degeneration, and rarely intranuclear inclusion bodies are observed only in basal cells of the epidermis [11]. This study aims to see the histopathological picture of tumor tissue collected from 2 different breeds of cattle.

\section{MATERIALS AND METHODS}

\subsection{Sample Collection}

Tumor tissue biopsy collected from 1 breed of Angus cattle and 1 breed of Limousin cattle aged 1 year each. Before the biopsy, the surrounding tissue was under anaesthesia with local anaesthetic (Lidocaine HCL). Furthermore, the sample was fixed in $10 \%$ neutral buffered formalin (NBF) solution and then made histopathological preparations.

\subsection{Histopathological Preparations}

Histopathological preparations were processed regarding the modification of the method of Kiernan [12]. Tumor samples were fixed in a $10 \%$ neutral buffer formalin (NBF) solution, then cut to a size of $1 \times 1 \times 1 \mathrm{~cm}$, dehydrated in an ethanol series with increasing concentrations $(70 \%, 80 \%, 96 \%$, absolute ethanol I and II) for 2 hours each. Then clearing with xylene I and II for 1.5 hours, then infiltrated with paraffin infiltration I and II for 2 hours each and then implanted in a paraffin block using a paraffin embedding set. The paraffin blocks were then cut to a thickness of $5 \mu \mathrm{m}$ using a microtome. The best cut results are floated in a water bath with a temperature of $45^{\circ} \mathrm{C}$. The preparation is then lifted and placed on the object-glass, then dried on a slide warmer for at least 2 hours.

\subsection{Histopathological Staining}

The tissue slides were deparaffinized using xylene I and II for 5 minutes. Then rehydrated with absolute ethanol I and II, 96\% ethanol I and II, 90\% ethanol I and II each for 3 minutes, then soaking in distilled water for 1 minute. Then stained by soaking in a solution of hematoxylin for 5 minutes, then rinsing with distilled water. After that, once to acid alcohol and then put in the eosin solution for 5 minutes. Then rinsed again with distilled water, then the dehydration process with $96 \%$ ethanol I and II, absolute ethanol I and II each dipping twice. After that, cleared with xylene I, II, III for 3 minutes, then mounted with adhesive material Entellan ${ }^{\circledR}$ slides. The observations were made with an Olympus light microscope and documented with a micrograph photo.

\section{RESULTS}

Observations of the breed of Angus cattle, show neoplasms such as cauliflower-like shaped that appear since they were 4 months old. Dry and rough. Initially, it grows on the neck and spreads to the face and shoulders with a nodular shape and sarcoid of varying sizes, and has never been treated. Limousin cattle were also found to have cauliflower-like shaped neoplasms with changing sizes from 1 month old. Initially, the neoplasm grew in the area around the lips and spread over the head, neck and shoulders (Figure 1) and had been treated with ivermectin (Interchemie ${ }^{\circledR}$, Netherlands) but did not heal.

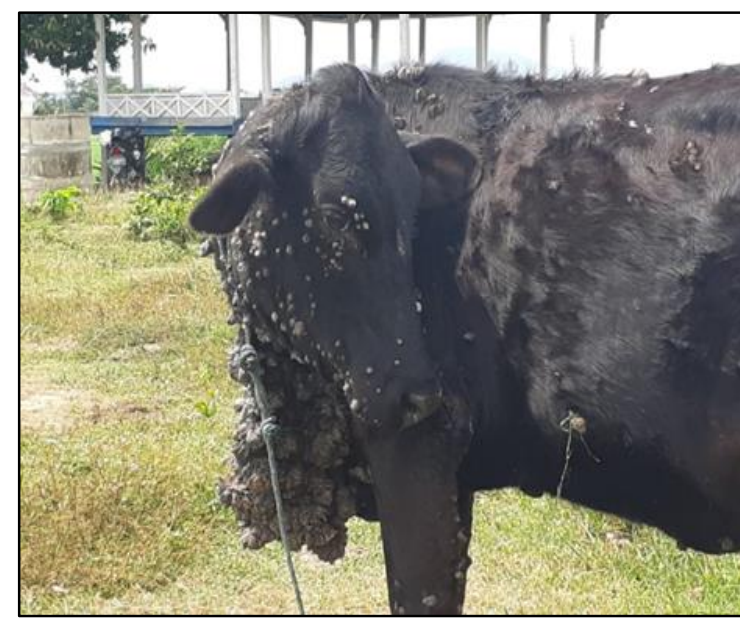

Figure 1 There is a cutaneous papilloma tumor in the head, neck, and shoulder area.

\subsection{Clinical Signs and Gross Pathology}

In Angus and Limousin cattle, a mass of cauliflower-like shaped, dry, rough was found with the distribution of the head, neck, eyes and shoulders with various size and exophytic. The Angus cattle patient found sarcoid-shaped papilloma in the neck area and nodular shapes with various sizes in the head and shoulder area. The color of the papilloma was grayish black and there was still hair on the tumor with rough tumor surface shape (Figure 2A). In the Limousin cattle patient, nodular papillomas were found on the head, neck and back of various sizes and yellowishwhite in color with rough surface shapes (Figure 2B).

\subsection{Histopathological Examination}

Histopathological examination, tumors in Angus and Limousin cattle found hyperkeratosis in the stratum corneum, acanthosis and rete ridge extending toward the connective tissue in the dermal (Figure 3A), hyper granulation of the stratum spinosum, and the presence of fibrovascular areas in the epidermal layer (Figure. 3B), squamous epithelial cell proliferation, koilocytes in the stratum spinosum (Figure 3C). A few 
mitotic (Figure. 3D) in Limousin tumors, and inclusion bodies in keratinocyte cells (Figure 4).

\section{DISCUSSION}

On clinical examination, the mass distribution of both Angus and limousin cattle patients did not differ from the results reported by Mansour et al. [13], which states that there are papillomas in the shoulder, head and neck area. However, it is different from the report of Al-Salihi et al. [14], papillomas in cattle aged 5 months to 5 years were found in all parts of the animal body. BPV infection, depending on the viral pathotype and environmental factors, causes clinical signs in cattle, such as skin fibropapilloma caused by BPV-1 and 2, upper gastrointestinal cancer caused by BPV-4, papillomatosis of the nipple and udder caused by BPV$1,-5,-6,-9$ and -10 , penis papillomatosis caused by BPV-1, bladder cancer caused by BPV-1 and 2 and skin papilloma caused by BPV-8 $[15,16]$.

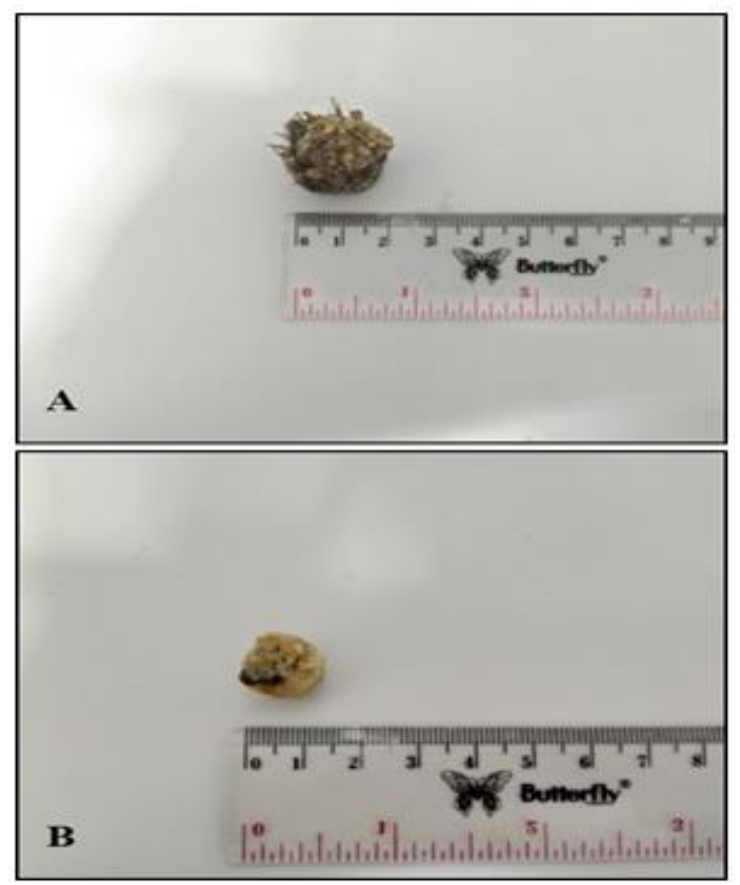

Figure 2 Macroscopic tumor such as cauliflowerlike shaped with a rough surface, grayish black in Angus cattle (A); Macroscopic tumor with a rough surface, yellowish-white and cauliflower-like shaped (B).

According to Araldi et al. [2], the presence of clinical lesions on the skin is a very important indicator for primary diagnosis that needs to be supported by histopathology. Histopathological analysis, papilloma (exophytic), there was moderate to severe hyperkeratosis, squamous epithelial cell proliferation such as finger-like shape in the fibrovascular area, as well as hypergranulosis in the granulosum stratum similar to the report Ayman and Das [17] and Al-Salihi et al. [13]. Microscopically, exophytic type fibropapilloma is the most common type and also endophytic type fibropapilloma which can lead to malignant fibrosarcoma [18].

Histopathologically, skin neoplasms caused by papillomavirus infection in cattle are different from other types of animals in skin epithelial hyperplasia. According to Cheville and Olson. [19], that the virus triggers a tissue response and cutaneous fibroplasia. Fibropapilloma of the reproductive tract is evident in the lesion following intradermal inoculation. However, the same lesions are not so obvious that they are not visible [20].
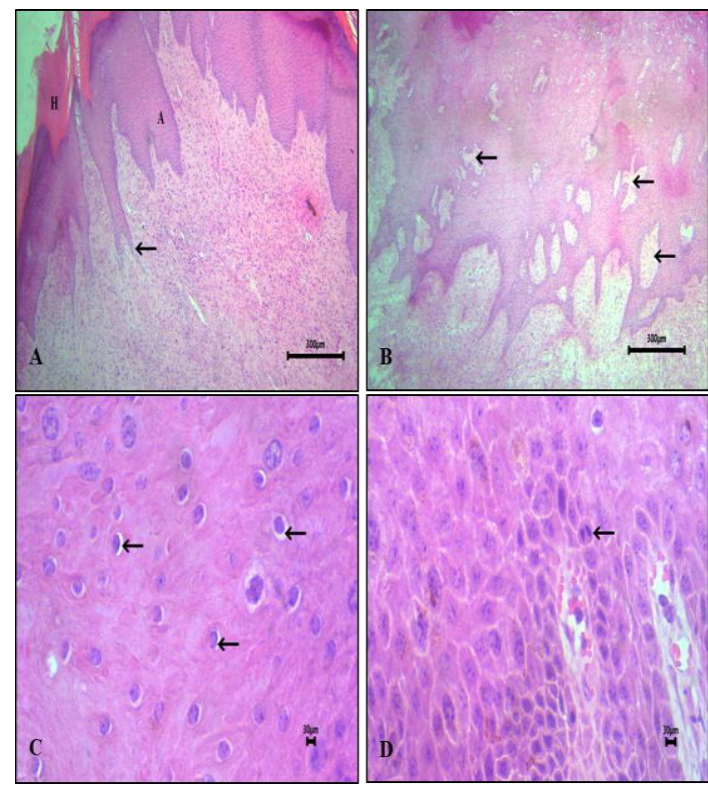

Figure 3 Hyperkeratosis in the stratum corneum $(\mathrm{H})$, acanthosis $(\mathrm{A})$ and rete ridge extending toward the connective tissue in the dermal (Arrow). Hematoxylin-Eosin (H\&E). x4; B. The presence of fibrovascular areas in the epidermal layer (Arrow). H\&E. $\mathrm{x} 4$; C. Degeneration of the vacuole cytoplasm (koilocytosis) in the stratum spinosum (Arrow). H\&E. x40; D. Mitotic cell in the stratum basale (Arrow). H\&E. 


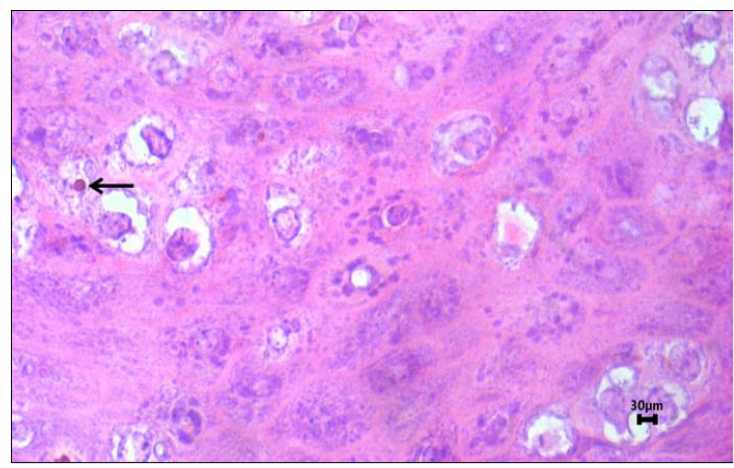

Figure 4 Eosinophilic intranuclear inclusions in keratinocyte cells (Arrow). Hematoxylin-Eosin (H\&E). x40.

Intranuclear inclusions in this study were found to be few. The same is the case with previous studies by Al-Salihi et al. and Tan [14,10]. According to Ozsoy et al. [11], found inclusion bodies in basal cells.

In the study results, histopathologically the two samples of cattle tumors are in the growing phase. There are 3 phases of cutaneous papilloma tumor development, namely: the growing phase, development phase and the regression phase. The growing phase is characterized by basal cell hyperplasia, mild to moderate acanthosis, hyperkeratosis and parakeratosis, and some intranuclear body inclusion. The developmental phase is characterized by acanthosis characterized by swollen cells and marked hyperkeratosis and parakeratosis. any intranuclear inclusion bodies were present in swollen or degenerating cells of the upper spinous and granular cell layers. The regression phase is characterized by slight epidermal hyperplasia, rete ridge regression, moderate fibroblast proliferation, and collagen deposition along with $\mathrm{T}$ lymphocyte infiltration in the epidermal and dermal layers [21].

\section{CONCLUSION}

The result of this study proves that found the differences by macroscopic and microscopic of the papilloma tumors in Angus and Limousin cattle.

\section{AUTHORS' CONTRIBUTIONS}

EW, RAS, and DA executed the experiment, analyzed the tissue. EW, NZ, DIH and AW interpretation of data the tissue. All authors interpreted and critically revised the manuscript for important intellectual contents and approved the final version.

\section{ACKNOWLEDGMENT}

The author is grateful to the Pathology Laboratory of the Faculty of Veterinary Medicine, Universitas Syiah Kuala, Banda Aceh and Animal Health Center,
Kajhu, Aceh Besar for their helpful contributions and suggestions.

\section{REFERENCES}

[1] V.S. Ataseven, O. Kanat, Y. Ergun, Molecular identification of bovine papillomaviruses in dairy and beef cattle: First description of $\mathrm{Xi}$-and Epsilonpapillomavirus in Turkey, Turk. J. Vet. Anim. Sci. 40 (2016) 757-763. DOI: https://doi.org/10.3906/vet-1512-64.

[2] R.P. Araldi, T.C. Melo, S.R. Consonni, Bovine papillomavirus productive infection in cell cultures: first evidences, Virol. Res. Rev. 1(2) (2017) 1-9. DOI: https://doi.org/10.15761/VRR.1000110.

[3] M. Alçı̆̆ır, M. Timurkan, The association between insulin-like growth factors I, II and bovine papillomavirus type-1 expressions in naturally occuring bovine fibropapilloma cases, Ankara Üniv Vet Fak Derg. 65 (2018) 115-22. DOI: https://doi.org/ 10.1501/vetfak_0000002836.

[4] M. Lunardi, A.A. Alfieri, R.A.A Otonel, B.K. de Alcântara, W.B. Rodrigues, A.B. de Miranda, A. F. Alfieri, Genetic characterization of a novel bovine papillomavirus member of the Deltapapillomavirus genus, Vet. Microbiol. 162 (1) (2013) 207-213. DOI: https://doi.org/10.1016/j.vetmic.2012.08.030.

[5] M.R. Ackermann, Sarcoids of horses. In: Zachary JF, McGavin MD (eds) Pathologic basis of veterinary disease, 5th edn. Elsevier Mosby, St. Louis, 2012, pp 125.

[6] P.A.A. Raj, S. Pavulraj, M.A. Kumar, S. Sangeetha, R. Shanmugapriya, S. Sabithabanu, Therapeutic evaluation of homeopathic treatment for canine oral papillomatosis, Vet. World. 13(1) (2012) 206-213. DOI: www.doi.org/10.14202/vetworld.2020.206-213.

[7] F. Bocaneti, G. Altamura, A. Corteggio, Detection of bovine papillomavirus -1/-2 DNA by classical PCR from spontaneous cutaneous fibropapillomas in cattle, Revista Romana de Medicina Veterinaria. 57 (1-2) (2014) 49-52.

[8] P.K Nicholls, M.A. Stanley, The immunology of animal papillomaviruses, Vet. Immunol. Immunopathol. 73 (2000) 101-127. DOI: https://doi.org/10.1016/S0165-2427(99)00165-8.

[9] A. Otter, D. Leonard, Fibropapillomatosis outbreak in calves., Vet. Record. 153(18) (2003) $570-571$. 
[10] M.T. Tan, B. Dagalp, A.H. Kirmizigula, A Histopathological, immunohistochemical and molecular study of cutaneous bovine papillomatosis, Kafkas Univ Vet Fak Derg. 18 (5) (2012) 739-744. DOI:10.9775/kvfd.2012.5341

[11] S.Y. Özsoy, Z. Özyildiz, M. Güzel, Clinical, pathological and immunohistochemical findings of bovine cutaneous papillomatosis, Ankara Üniv. Vet. Fak Derg. 58 (2011) 161-165.

[12] J.A. Kiernan, Histological \& Histochemical Methods: Theory and Practice. 2nd edition. Pergamon Press, Oxford, UK, New York, 1990.

[13] K.A. Mansour, Clinical, histopathological and molecular detection of cutaneous papillomatosis associated with bovine papillomavirus types 1and 2 in cattle from Al-Qadissiyia province, Kufa J. Vet. Med. Sci. 7(1) (2016) 182-191.

[14] K.A. AL-Salihi, A.H. Al-Dabhawi, A.A. Ajeel, I.A. Erzuki, T.A.H. Ali, Clinico-histopathological and immunohistoc-hemical study of ruminant's cutaneous papillomavirus in Iraq, Vet. Med. Int. (2020) 1-11. DOI: https://doi.org/10.1155/2020/5691974.

[15] G. Borzacchiello, F. Roperto, Bovine papilloma viruses, papillomas and cancer in cattle, Vet. Res. 39 (5) (2008) 1-10. DOI: https://doi.org/10.1051/vetres:2008022.
[16] C.C. Tozato, M. Lunardi, A.F. Alfieri, R.A. Otonel, G.W. Di Santis, B.K.D. Alcantara, A.A. Alfieri, Teat papillomatosis associated with bovine papillomavirus types $6,7,9$, and 10 in dairy cattle from Brazil, Braz. J. Microbiol. 44 (3) (2014) 905-909. DOI: http://dx.doi.org/10.1590/S151783822013005000057.

[17] U. Ayman, S.K Das, Histo-morphology of cutaneous papillomatosis in indigenous cattle, Bangl. J. Vet. Med. 17 (1) (2019) 47-52. DOI: https://doi.org/10.33109/bjvmjj19fam2.

[18] B.L. Jangir, R.B. Bindi, P. Kumari, R. Somvanshi, Pathological studies and detection of different bovine papilloma virus types in buffalo cutaneous warts, Turk. J. Vet. Anim. Sci. 41 (2017) 306-311. DOI: $10.3906 /$ vet-1605-17

[19] N.F. Cheville, C. Olson, Epithelial and fibroblastic proliferation in bovine cutaneous papillomatosis. Vet. Pathol. (1964) 248-257. DOI: https://doi.org/10.1177/ 030098586400100304.

[20] S.W. Barthold, L.D. Koller, C. Olson, E. Studer, A. Holtan, A typical warts in cattle, JAVMA. 165 (3) (1974) 276-280.

[21] [21] D.J. Meuten, Tumors in domestic animals. John Wiley \& Sons, Iowa, 2016, pp 91-97. 